\title{
The E2F-Cdc2 Cell-Cycle Pathway Specifically Mediates Activity Deprivation-Induced Apoptosis of Postmitotic Neurons
}

\author{
Yoshiyuki Konishi and Azad Bonni \\ Department of Pathology, Harvard Medical School, Boston, Massachusetts 02115
}

\begin{abstract}
Neuronal apoptosis plays a critical role in the normal development of the mammalian brain and is thought to contribute to the pathogenesis of several neurologic disorders. However, the intracellular mechanisms underlying apoptosis of neurons remain incompletely understood. In the present study, we characterized a cell-cycle-based mechanism by which neuronal activity deprivation induces apoptosis of postmitotic neurons. Activity deprivation, but not growth factor withdrawal, was found to induce Cdc2 expression and consequent Cdc2-mediated apoptosis in granule neurons of the developing rat cerebellum. We found that activity deprivation induces $c d c 2$ transcription in neurons via an E2F-binding element (EBE) within the $c d c 2$ promoter. The transcription factor E2F1 that is expressed in granule neurons was found in DNA binding assays to bind to the EBE of the $c d c 2$ gene. In chromatin immunoprecipitation analysis, endogenous E2F1 forms a complex with the promoter of the endogenous $c d c 2$ gene in granule neurons, indicating that endogenous E2F1 is poised to activate transcription of the endogenous $c d c 2$ gene in neurons. Consistent with this conclusion, a dominant interfering form of E2F, when expressed in granule neurons, blocked activity deprivation-induced $c d c 2$ transcription. In other experiments, we found that the expression of $\mathrm{E} 2 \mathrm{~F} 1$ in granule neurons induces $\mathrm{Cdc} 2$ expression and promotes neuronal apoptosis via the activation of Cdc2. Remarkably, in contrast to inducing the E2F-mediated expression and activation of $\mathrm{Cdc} 2$ in granule neurons, activity deprivation fails to stimulate the expression of E2F-target genes that trigger DNA synthesis and replication. Together, our findings define a novel apoptotic mechanism whereby E2F selectively couples an activity deprivation-induced signal to $c d c 2$ transcription in the absence of stimulating DNA synthesis and thus culminating in Cdc2-mediated apoptosis of postmitotic neurons.
\end{abstract}

Key words: Cdc2; E2F; apoptosis; neuron; activity; transcription; cell cycle; promoter

\section{Introduction}

During the development of the mammalian brain, the generation of neurons from their precursor cells coincides with their exit from the cell cycle (Caviness et al., 1995; McConnell, 1995). Although postmitotic neurons do not undergo cell division, they continue to express components of the cell cycle for some time after their terminal differentiation (Freeman et al., 1994; Vincent et al., 1997; Busser et al., 1998; Padmanabhan et al., 1999). Accumulating evidence suggests that these cell-cycle proteins play a key role in programmed cell death or apoptosis of postmitotic neurons that is critical to the normal development of the mammalian brain (for review, see Liu and Greene, 2001a). However, the intracellular mechanisms that trigger reactivation of components of the cell cycle in postmitotic neurons remain to be elucidated. In addition, the mechanisms by which cell-cycle proteins induce apoptosis of neurons remain incompletely understood.

Within the developing brain, the cerebellar granule neuron

\footnotetext{
Received Aug. 16, 2002; revised Nov. 14, 2002; accepted Dec. 6, 2002

This work was supported by a Burroughs Wellcome Career Development Award (A.B.) and by National Institutes of Health Grant R01-NS41021-01 (A.B.). A.B. is the recipient of an Alfred P. Sloan Foundation Fellowship, a Robert H. Ebert Clinical Scholar Award from the Esther A. and Joseph Klingenstein Fund, an EJLB Foundation Award, and a Sidney Kimmel Foundation Award. We thank B. Gaudilliere for critical reading of this manuscript, P. Hinds for helpfu discussions, C. K. Glass for providing the cdc2-luciferase plasmids, W. Sellers for providing the E2F1 expression plasmids, and S. Vasquez for technical assistance.

Correspondence should be addressed to Azad Bonni, Department of Pathology, Harvard Medical School, 200 Longwood Avenue, Boston, MA 02115. E-mail: azad_bonni@hms.harvard.edu.

Copyright $\odot 2003$ Society for Neuroscience $\quad 0270-6474 / 03 / 231649-10 \$ 15.00 / 0$
}

population has been widely used to characterize the cellular and molecular mechanisms of neuronal apoptosis. Proliferating granule neuron precursors differentiate into postmitotic granule neurons within the external granule cell layer (EGL) of the developing cerebellum (Hatten and Heintz, 1995). Newly generated granule neurons migrate from the EGL into the underlying internal granule cell layer (IGL) where they take on the properties of mature granule neurons (Altman and Bayer, 1997). Granule neuron apoptosis is observed in both the EGL and IGL, peaking in the first to second week of the postnatal rat cerebellum (Wood et al., 1993).

Granule neurons cultured from the rat cerebellum undergo apoptosis that is suppressed by neuronal activity and growth factors (D’Mello et al., 1993, 1997; Galli et al., 1995; Miller and Johnson, 1996). Growth factors are typically provided by serum or by a high concentration of insulin that activates the insulinlike growth factor 1 (IGF1) receptor (Cohick and Clemmons, 1993; Alessi et al., 1996). Neuronal activity is mimicked by a high concentration of extracellular $\mathrm{KCl}$ that triggers membrane depolarization leading to the entry of calcium through voltagesensitive calcium channels (VSCCs) (Catterall, 2000). Granule neurons undergo apoptosis when they are deprived of membrane-depolarizing concentrations of $\mathrm{KCl}$ or when they are deprived of growth factors. The mechanisms by which activity deprivation or growth factor withdrawal induces apoptosis are beginning to be characterized (Watson et al., 1998; Levkovitz and Baraban, 2001; Yamagishi et al., 2001; Putcha et al., 2002). An 
important question that remains to be addressed is whether there is specificity in the mechanisms that mediate activity deprivation-induced or growth factor withdrawal-induced neuronal apoptosis.

Recently, we reported that in newly differentiated cerebellar granule neurons, neuronal activity deprivation triggers the activation of the protein kinase $\mathrm{Cdc} 2$, a cyclin-dependent kinase with an established function in driving proliferating cells through mitosis (Konishi et al., 2002). In granule neurons, activated Cdc2 mediates activity deprivation-induced apoptosis by directly phosphorylating the $\mathrm{BH} 3$-only protein $\mathrm{Bcl}$-2-associated death promoter (BAD) at a distinct site, serine 128 , and thereby activating $\mathrm{BAD}$-mediated apoptosis (Konishi et al., 2002). Thus, reactivation of the cell-cycle component $\mathrm{Cdc} 2$ by neuronal activity deprivation directly activates the cell death machinery. A major question that was raised by these findings is: how is Cdc2 activity regulated in postmitotic neurons? In particular, how does neuronal activity deprivation induce the activity of Cdc2 in postmitotic neurons, thereby triggering apoptosis?

In this study, we characterized a specific mechanism by which activity deprivation induces neuronal apoptosis. We found that activity deprivation, but not growth factor withdrawal, induces the expression of Cdc2 in granule neurons, and that Cdc2 activity specifically mediates activity deprivation-induced neuronal apoptosis. Activity deprivation was found to induce $c d c 2$ transcription in granule neurons via a regulatory site within the $c d c 2$ promoter that binds the transcription factor E2F1. In chromatin immunoprecipitation analyses, we found that endogenous E2F1 in cerebellar granule neurons forms a complex with the promoter of the endogenous $c d c 2$ gene, suggesting that the $c d c 2$ gene is a target of endogenous E2F1 in cerebellar granule neurons. Consistent with this interpretation, the expression of a dominant interfering form of E2F was found to inhibit activity deprivationinduced $c d c 2$ transcription in granule neurons. In other experiments, we found that the expression of E2F1 in granule neurons induces the expression of endogenous $\mathrm{Cdc} 2$ and triggers apoptosis. The E2F1-induced apoptosis was found to be reduced significantly by coexpression of a dominant interfering form of Cdc2. Together, our findings define the E2F-Cdc2 cell-cycle pathway as a novel and specific mechanism by which activity deprivation induces apoptosis of postmitotic neurons. In proliferating cells, E2F is believed to regulate the expression of a large set of genes that drive these cells through the cell cycle (DeGregori et al., 1995; Dyson, 1998; Harbour and Dean, 2000; Ishida et al., 2001; Ren et al., 2002). In contrast, activity deprivation of granule neurons fails to induce the set of E2F-regulated genes serving a role in DNA synthesis and replication. We conclude that the $c d c 2$ gene represents a select target of E2F in activity-deprived postmitotic neurons, and that the activation of $\mathrm{Cdc} 2$ in the absence of DNA synthesis in postmitotic neurons might signal apoptosis in a similar manner to unscheduled Cdc2 activation in proliferating cells (Shi et al., 1994).

\section{Materials and Methods}

Antibodies. Mouse monoclonal antibodies to $\mathrm{Cdc} 2$ and actin and rabbit polyclonal antibody to $\mathrm{BAD}, \mathrm{E} 2 \mathrm{~F} 1$, proliferating cell nuclear antigen (PCNA), Cdk2, and hemagglutinin (HA) were obtained from Santa Cruz Biotechnology (Santa Cruz, CA). The mouse monoclonal antibody to $\beta$-galactosidase (Promega, Madison, WI) and cleaved caspase-3 (Cell Signaling, Beverly, MA) were also purchased. The phospho128-BAD antibody was described previously (Konishi et al., 2002).

Cerebellar granule neuron cultures and transfections. Cerebellar granule neurons were prepared as described previously (Bonni et al., 1999). One day after preparation, cytosine arabinofuranoside (AraC) $(10 \mu \mathrm{M})$ was added to inhibit proliferation of non-neuronal cells. Transfection of granule neuron cultures was done using a modified calcium phosphate method as described previously (Konishi et al., 2002). In the experiments in Figure $2 A, 0.1 \mu \mathrm{g}$ of $c d c 2$-firefly luciferase reporter plasmid and 0.02 $\mu \mathrm{g}$ of elongation factor (EF)-renilla luciferase together with $0.5 \mu \mathrm{g}$ of carrier plasmid were transfected. In the experiments in Figure $3 A, 0.1 \mu \mathrm{g}$ of $c d c 2$-firefly luciferase plasmid, $0.02 \mu \mathrm{g}$ of EF-renilla luciferase plasmid, and $1 \mu \mathrm{g}$ of E2F1 expression plasmid were transfected. In the experiments in Figure $3, B$ and $C, 1 \mu \mathrm{g}$ of green fluorescent protein (GFP) plasmid, $0.25 \mu \mathrm{g}$ of $\beta$-galactosidase expression plasmid, and $1 \mu \mathrm{g}$ of E2F1 expression plasmid were transfected. In the experiments in Figure $4 A-G$, $2 \mu \mathrm{g}$ of E2F1 expression plasmid was transfected. In the experiments in Figure $4 I, 0.1 \mu \mathrm{g}$ of $c d c 2$-firefly luciferase plasmid, $0.02 \mu \mathrm{g}$ of EF-renilla luciferase, and $0.1 \mu \mathrm{g}$ of E2F-Rb expression plasmid together with $0.5 \mu \mathrm{g}$ of carrier plasmid were transfected. In the experiments in Figure $4 \mathrm{~J}, 1 \mu \mathrm{g}$ of E2F-Rb or the vector plasmid together with $0.25 \mu \mathrm{g}$ of $\beta$-galactosidase expression plasmid were transfected. In the experiments in Figure $5 A-E$, $0.5 \mu \mathrm{g}$ of E2F1 expression plasmid and $0.25 \mu \mathrm{g}$ of $\beta$-galactosidase expression plasmid were transfected. In the experiments in Figure $5 F, 0.5 \mu \mathrm{g}$ of E2F1 expression plasmid, $0.5 \mu \mathrm{g}$ of a dominant interfering form of Cdc2 (Cdc2-DN) expression plasmid, and $0.25 \mu \mathrm{g}$ of $\beta$-galactosidase expression plasmid were transfected.

Western blot analysis. For Western blot analysis, cerebellar granule neurons were harvested with a lysis buffer containing $20 \mathrm{~mm}$ Tris- $\mathrm{HCl}$, $\mathrm{pH} 7.5,150 \mathrm{~mm} \mathrm{NaCl}, 1 \%$ Triton X-100, 5 mм EGTA, $25 \mathrm{~mm}$ $\beta$-glycerophosphate, $1 \mathrm{~mm}$ DTT, $1 \mathrm{~mm}$ PMSF, $1 \mathrm{~mm} \mathrm{NaVO}_{3}$, and protease inhibitors. Protein amounts were measured by a Bradford assay. Equal amounts of proteins were separated by SDS-PAGE and transferred to nitrocellulose membranes. Immunoblotting was performed as described previously (Bonni et al., 1999).

Immunocytochemistry. In the experiments in Figures $3, B$ and $C$, and $4 A-G$, cerebellar granule neurons were fixed in $4 \%$ paraformaldehyde for $20 \mathrm{~min}$ at room temperature. Neurons were washed twice with PBS and permeabilized with PBS containing 0.4\% Triton X-100 for $20 \mathrm{~min}$, followed by blocking with TBS containing $0.02 \%$ Tween 20 and $10 \%$ milk for $1 \mathrm{hr}$ at room temperature. Primary antibody incubations were performed at $4^{\circ} \mathrm{C}$ overnight in TBS containing $0.02 \%$ Tween 20 and 3\% bovine serum albumin. In experiments in which bromodeoxyuridine (BrdU) incorporation was measured in Figure $6 A-D$, cells were fixed with a mixture of ethanol and glycine solution at $-20^{\circ} \mathrm{C}$ for $20 \mathrm{~min}$. Immunocytochemistry for BrdU was performed as described in the Labeling and Detection Kit I (Roche Diagnostics, Indianapolis, IN).

Neuronal survival and apoptosis assays. In the experiments in Figures $4 \mathrm{~J}$ and 5 , transfected cerebellar granule neurons were fixed in $4 \%$ paraformaldehyde. Indirect immunofluorescence was performed using an antibody to $\beta$-galactosidase to visualize transfected neurons. Neuronal survival and apoptosis were assessed in $\beta$-galactosidase-expressing neurons based on the integrity of neurites and integrity of the nucleus as determined by the staining with DNA dye bisbenzimide (Hoechst 33258) as described previously (Konishi et al., 2002). Cell counts were performed in a blinded manner.

Electrophoretic mobility shift assays. Electrophoretic mobility shift assays (EMSAs) were performed as described previously (Campanero et al., 1999). Nuclear extracts from cerebellar granule neurons were prepared as described previously (Schreiber et al., 1989). The DNA probe was prepared by annealing the following oligonucleotides: $5^{\prime}$-TTCCTCTTTCTTTCGCGCTCTAGCCACC-3' and 5'-GGGTGGGCTAGAGCGCGAAAGAAAGAGGA-3'. Nuclear extracts of cerebellar granule neurons $(5 \mu \mathrm{g})$ were incubated in $10 \mu \mathrm{l}$ of a preincubation mixture containing 20 mм HEPES/KOH, pH 7.9, 20\% glycerol, 0.1 м KCl, 0.2 mм EDTA, 0.5 mM DTT, and $0.2 \mu \mathrm{g}$ of sheared herring sperm DNA for $30 \mathrm{~min}$ on ice. After preincubation, $0.1 \mathrm{ng}$ of the radiolabeled probe was added to the reaction mixture and incubated for $30 \mathrm{~min}$ on ice. In competition assays, cold wild-type E2F-binding element (EBE) probe or a mutant EBE probe in which CG (underlined in the sequence above) was replaced by AT was added to the preincubation mixture. For reactions including antibodies, rabbit antibody that recognizes E2F1 specifically or a control rabbit anti-HA antibody was added to the preincubation mixture. DNA-protein complexes were analyzed on a $4 \%$ polyacrylamide- $0.1 \%$ bisacryl- 
amide nondenaturing gel in $0.5 \%$ Tris-borate-EDTA at $4^{\circ} \mathrm{C}$. The gel was dried and analyzed by autoradiography.

Chromatin immunoprecipitation assays. Chromatin immunoprecipitation assays were performed as described previously (Takahashi et al., 2000; Rayman et al., 2002). Approximately $4.5 \times 10^{7}$ cerebellar granule neurons were used in each reaction. Chromatin prepared from granule neurons was precipitated using $4 \mu \mathrm{g}$ of rabbit antibody that recognizes E2F1 specifically or control anti-HA antibody together with protein A-Sepharose at $4^{\circ} \mathrm{C}$ overnight. Precipitated chromatin was treated with proteinase $\mathrm{K}$ and $\mathrm{RNase} \mathrm{A}$ at $55^{\circ} \mathrm{C}$ for $3 \mathrm{hr}$ followed by overnight incubation at $65^{\circ} \mathrm{C}$ to reverse cross-linking. Primers used for PCR that anneal to the rat $c d c 2$ promoter in a region encompassing the EBE were designed as follows: 5' -CTGAGCTCAAGAGTCAGTTGGCG-3' and 5' -CGCCAATCCGATTGCACGTAGAC- $3^{\prime}$. PCRs were performed using $1 / 20$ th of chromatin precipitates. PCR products were labeled with $\left[\alpha^{32}-\mathrm{P}\right] \mathrm{dCTP}$ and detected by autoradiography. Experiments were performed three times using chromatin that was prepared independently.

\section{Results}

Cdc2 specifically mediates activity deprivation-induced granule neuron apoptosis

We recently characterized the Cdc2-BAD signaling pathway as a novel apoptotic mechanism that is activated in newly generated cerebellar granule neurons with the suppression of neuronal activity (Konishi et al., 2002). Because common signaling mechanisms typically mediate apoptosis of neurons during trophic factor withdrawal, we tested whether the Cdc2-BAD apoptotic pathway is also activated in neurons during growth factor withdrawal.

Cerebellar granule neurons were prepared from postnatal day 6 (P6) rat pups and cultured in the presence of serum and high concentrations of $\mathrm{KCl}(30 \mathrm{~mm})$ that induce membrane depolarization and consequent activation of VSCCs. We first characterized the activation of the Cdc2-BAD pathway in activitydeprived granule neurons. After $2 \mathrm{~d}$ in vitro (DIV), granule neuron cultures (P6 plus 2 DIV) were placed in survival medium [Basal Medium Eagle (BME) plus $30 \mathrm{~mm} \mathrm{KCl}$ plus serum] or were deprived of membrane-depolarizing concentrations of $\mathrm{KCl}$ (BME plus $5 \mathrm{~mm} \mathrm{KCl}$ plus serum). After $24 \mathrm{hr}$, cultures were subjected to Western blot analysis using an antibody to $\mathrm{Cdc} 2$, an antibody that recognizes the serine 128 phosphorylated form of BAD specifically (phospho128-BAD antibody), or an antibody that recognizes $\mathrm{BAD}$ regardless of its phosphorylation state $(\mathrm{N}-20$ $\mathrm{BAD}$ antibody). Activity deprivation induced the expression of endogenous $\mathrm{Cdc} 2$ protein and induced the phosphorylation of endogenous $\mathrm{BAD}$ at serine 128 in granule neurons (Fig. $1 \mathrm{~A}$, lanes 1 and 2) (Konishi et al., 2002).

We next tested whether growth factor withdrawal also induces $\mathrm{Cdc} 2$ expression and BAD serine 128 phosphorylation in neurons. Activation of the IGF1 receptor by a high concentration of insulin $(10 \mu \mathrm{g} / \mathrm{ml})$ in granule neurons provides a prototypical growth factor-induced survival signal in granule neurons (D’Mello et al., 1993; Dudek et al., 1997). P6 plus 2 DIV granule neurons were placed in survival medium (BME plus $30 \mathrm{~mm} \mathrm{KCl}$ plus insulin) or were deprived of growth factor signaling (BME plus $30 \mathrm{~mm} \mathrm{KCl}$ ). Surprisingly, we found that growth factor withdrawal failed to induce the expression of Cdc2 and failed to induce the phosphorylation of $\mathrm{BAD}$ at serine 128 (Fig. $1 \mathrm{~A}$, lanes 3 and 4).

In assays of cell survival, inhibition of Cdc2 activity by roscovitine protected cerebellar granule neurons from activity deprivation-induced apoptosis (Fig. 1B) (Konishi et al., 2002) but failed to protect granule neurons against growth factor withdrawal-induced apoptosis (Fig. $1 B$ ), suggesting that $\mathrm{Cdc2}$ is
A

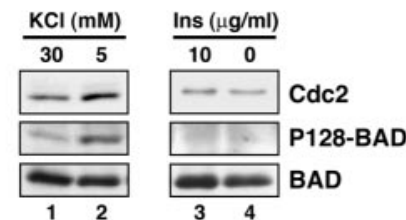

D

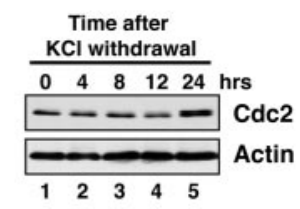

B

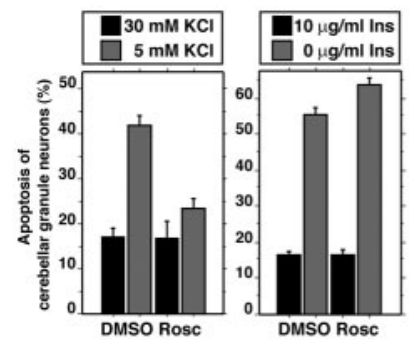

E

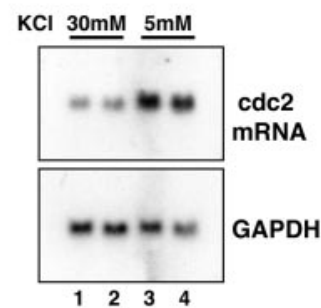

C

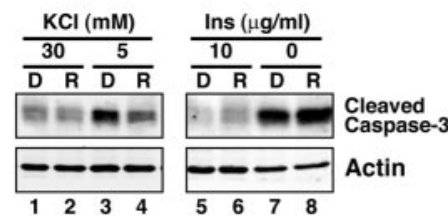

Figure 1. Cdc2 specifically mediates activity deprivation-induced apoptosis of cerebellar granule neurons. $A$, Lysates of granule neuron cultures ( $\mathrm{P} 6$ plus $2 \mathrm{DIV}$ ) that were in survival medium [30 $\mathrm{mm} \mathrm{KCl}$ plus serum, lane 1; $30 \mathrm{~mm} \mathrm{KCl}$ plus insulin (Ins), lane 3)], that were deprived of KCl ( $5 \mathrm{~mm} \mathrm{KCl}$ plus serum, lane 2), or that were deprived of growth factors ( $30 \mathrm{~mm} \mathrm{KCl}$, lane 4 ) for $24 \mathrm{hr}$ were immunoblotted with a mouse monoclonal antibody that recognizes (dc2 (top), the rabbit phospho128 (P128)-BAD antibody (middle), or an antibody that recognizes BAD regardless of its phosphorylation (bottom). Activity withdrawal significantly induced the expression of $\mathrm{Cdc2}(1.4 \pm 0.1 \mathrm{fold} ; n=3 ; p<0.001 ; \mathrm{ANOVA})$ and the phosphorylation of $\mathrm{BAD}$ at serine 128 (1.9 \pm 0.1 fold; $n=3$; ANOVA; $p<0.001)$, but insulin withdrawal failed to induce Cdc2 expression ( $0.8 \pm 0.1$ fold $; n=3$ ) or to induce the BAD serine 128 phosphorylation $(1.1 \pm$ 0.2 fold; $n=3$ ). $B$, Cerebellar granule neurons (P6 plus 2 DIV) were kept in survival medium ( 30 $\mathrm{mm} \mathrm{KCl}$ plus serum, left; $30 \mathrm{~mm} \mathrm{KCl} \mathrm{plus} \mathrm{insulin,} \mathrm{right)} \mathrm{or} \mathrm{were} \mathrm{deprived} \mathrm{for} 48 \mathrm{hr}$ of KCI ( $5 \mathrm{~mm} \mathrm{KCl}$ plus serum, left) or insulin ( $30 \mathrm{~mm} \mathrm{KCl}$, right) in the presence of the $\mathrm{Cdc} 2$ inhibitor roscovitine (Rosc; $10 \mu \mathrm{M}$ ) or its vehicle [dimethylsulfoxide (DMSO)]. Roscovitine inhibited neuronal activity deprivation-induced apoptosis (mean \pm SEM; $n=3 ;$ ANOVA; $p<0.01$ ) but not growth factor withdrawal-induced apoptosis. C, Lysates of cerebellar granule neurons (P6 plus 2 DIV) that were treated as in $B$ in the presence of DMSO $(D)$ or roscovitine $(R)$ were immunoblotted using an antibody to the cleaved form of caspase-3 (top) or an antibody that recognizes actin (bottom) to serve as control for equal protein loading. $D$, Lysates of cerebellar granule neurons that were placed in full medium ( $30 \mathrm{~mm} \mathrm{KCl}$ plus serum) or deprived of $\mathrm{KCI}$ ( $5 \mathrm{~mm} \mathrm{KCl} \mathrm{plus} \mathrm{serum)} \mathrm{for} \mathrm{the}$ indicated times were immunoblotted with the antibody to $\mathrm{Cdc2}$ (top) or the antibody to actin (bottom). E, Northern blot analysis of total RNA from cerebellar granule neuron cultures that had either been maintained in full medium ( $30 \mathrm{~mm} \mathrm{KCl} \mathrm{plus} \mathrm{serum,} \mathrm{lanes} 1$ and 2) or deprived of activity ( $5 \mathrm{~mm} \mathrm{KCl}$ plus serum, lanes 3 and 4 ) for $24 \mathrm{hr}$. RNA was subjected to Northern blot analysis using a cdc2 probe (top) or glyceraldehyde-3-phosphate dehydrogenase (GAPDH; bottom).

not required for growth factor withdrawal-induced neuronal apoptosis. In other experiments, both activity deprivation and growth factor withdrawal triggered the accumulation of the cleaved product of the protease caspase- 3 that reflects caspase- 3 activation (Fig. 1C) (Di Cunto et al., 2000). However, consistent with results of the cell-survival assays, although the inhibition of Cdc2 by roscovitine inhibited activity deprivation-induced caspase-3 cleavage, roscovitine failed to inhibit growth factor withdrawal-induced caspase- 3 cleavage (Fig. 1C). We also found that expression of Cdc2-DN that blocks activity deprivationinduced neuronal apoptosis (van den Heuvel and Harlow, 1993; Konishi et al., 2002) failed to inhibit granule neuron apoptosis 
after insulin withdrawal (data not shown). Together, these results indicate that activity deprivation selectively induces the Cdc2$\mathrm{BAD}$ apoptotic pathway and that $\mathrm{Cdc} 2$ promotes apoptosis specifically after neuronal activity deprivation but does not mediate growth factor withdrawal-induced apoptosis of cerebellar granule neurons.

\section{Activity deprivation induces $c d c 2$ transcription in granule neurons via an E2F-binding element within the $c d c 2$ promoter}

Having identified the Cdc2-BAD pathway as a specific mediator of activity deprivation-induced neuronal apoptosis, we focused our attention on the characterization of the mechanism by which activity deprivation induces the expression and consequent activation of Cdc2 in granule neurons. We performed a kinetic analysis of activity deprivation-induced Cdc2 protein expression in granule neurons, and found that the induction of Cdc2 protein was not apparent in the first $12 \mathrm{hr}$ but became evident $24 \mathrm{hr}$ after $\mathrm{KCl}$ withdrawal (Fig. $1 \mathrm{D}$ ). The elevated levels of Cdc2 were maintained thereafter at 48 and $72 \mathrm{hr}$ after the $\mathrm{KCl}$ withdrawal (see Fig. 6) (data not shown). The kinetics of activity deprivation-induced Cdc2 expression is characteristic of a late response gene. To distinguish between the two major possibilities that activity deprivation induction of $\mathrm{Cdc} 2$ occurs via a mechanism that is predominantly at the level of protein turnover or translation or at the level of transcription or mRNA processing, we characterized the effect of activity deprivation on the amount of $c d c 2$ mRNA in granule neurons. We found that the expression of $c d c 2$ mRNA was robustly induced in granule neurons $24 \mathrm{hr}$ after $\mathrm{KCl}$ withdrawal (Fig. $1 E$ ). Together, these results suggest that activity deprivation induces the expression of $\mathrm{Cdc} 2$ via an alteration in $c d c 2$ transcription or mRNA turnover.

We next determined whether activity deprivation regulates $c d c 2$ expression at the transcriptional level. In transient transfection experiments in granule neurons, we tested the effect of activity deprivation on the activity of a luciferase reporter gene that contains $3.2 \mathrm{~kb}$ of the $5^{\prime}$ regulatory sequence of the $c d c 2$ gene $(-3200 / c d c 2)$ (Sugarman et al., 1995). We found that $\mathrm{KCl}$ withdrawal robustly stimulated the expression of the $-3200 / c d c 2-$ luciferase reporter gene in granule neurons (Fig. $2 \mathrm{~A}$ ). These results suggest that activity deprivation stimulates Cdc2 expression by inducing $c d c 2$ transcription.

Deletion analysis of the $c d c 2$ promoter in granule neurons revealed that the region of the promoter between nucleotide -245 and nucleotide -94 relative to the transcriptional start site of the $c d c 2$ gene plays a critical role in activity withdrawalinduced $c d c 2$ transcription. The basal level of $c d c 2$ promotermediated transcription in membrane-depolarized granule neurons was not affected by the $5^{\prime}$ deletion mutants (Fig. $2 A$ ). These results argue against the interpretation that activity deprivation in granule neurons triggers the derepression of the $c d c 2$ promoter. Rather, these results suggest that activity deprivation induces the activity of a transcription factor that stimulates $c d c 2$ transcription in granule neurons.

We next focused our effort on identifying the site within the -245 to -94 region of the $c d c 2$ promoter that mediates activity deprivation-induced $c d c 2$ transcription. This region of the $c d c 2$ promoter contains an $\mathrm{EBE}$ at -128 that is conserved in the rat and human $c d c 2$ genes. The EBE plays an important role in mediating $c d c 2$ transcription in proliferating cells (Dalton, 1992; Shimizu et al., 1995). We therefore asked whether the EBE might mediate $c d c 2$ transcription in the postmitotic granule neurons after $\mathrm{KCl}$ withdrawal. We found that mutation of the EBE within

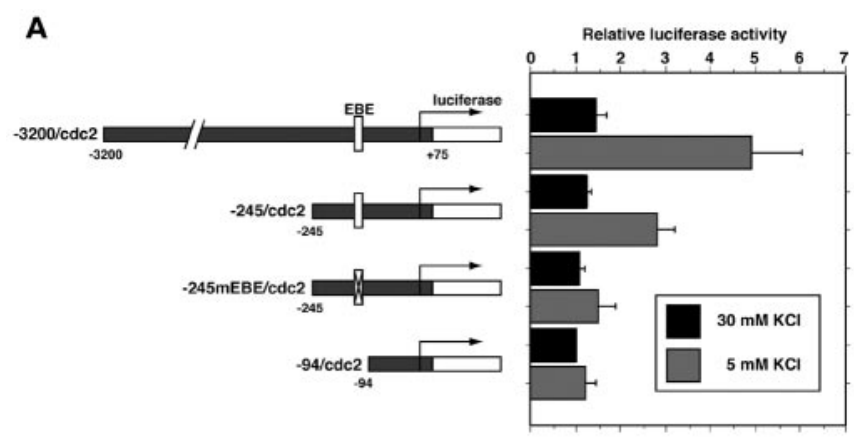

B

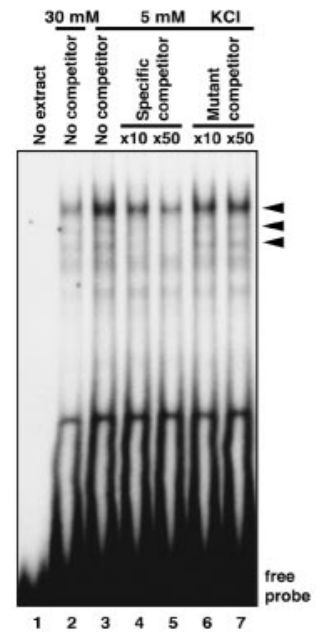

C

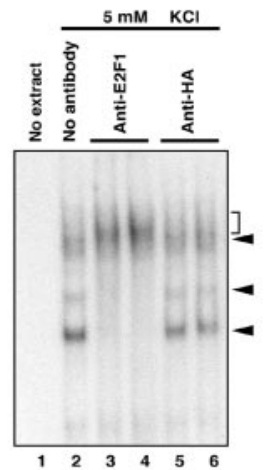

Figure 2. Activity deprivation induces $c d c 2$ transcription via an EBE within the $c d c 2$ promoter. $A$, Schematic representation of $c d c 2$ promoter-luciferase reporter constructs and their activity in cerebellar granule neurons. Cerebellar granule neurons (P6 plus 2 DIV) were transfected with the indicated $c d c 2$ firefly-luciferase reporter plasmid and reporter gene that is controlled by the elongation factor promoter (EF-renilla) and incubated for $4-5 \mathrm{hr}$ in conditioned full medium (30 mM KCl plus serum). Transfected neurons were then placed in full medium ( $30 \mathrm{~mm} \mathrm{KCl}$ plus serum; black bars) or deprived of neuronal activity ( $5 \mathrm{~mm} \mathrm{KCl}$ plus serum; gray bars) for $36 \mathrm{hr}$ and then subjected to dual-luciferase assay (Promega). The normalized firefly-luciferase activity of each $c d c 2$ luciferase reporter gene is shown relative to the activity of $-94 / c d c 2$ luciferase gene in membrane-depolarized granule neuron cultures. Values shown are mean \pm SEM $(n=4)$. Activity deprivation significantly increased the expression of the $-3200 / c_{c} 2$ and $-245 / c_{d c 2}$ reporter genes (ANOVA; $p<0.05$ ) but not of the $-245 \mathrm{mEBE} / \mathrm{cdc} 2$ or the $-94 / \mathrm{cdc} 2$ reporter genes. $B$, Nuclear extracts prepared from cerebellar granule neuron cultures (P6 plus 2 DIV) maintained in full survival medium ( $30 \mathrm{~mm} \mathrm{KCl}$ plus serum) or deprived of neuronal activity ( $5 \mathrm{~mm} \mathrm{KCl}$ plus serum) for $24 \mathrm{hr}$ were subjected to an EMSA. The radiolabeled probe contains the EBE within the $c d c 2$ promoter. For competition analysis, excess amount of wild-type cold probe (lanes 4 and 5) or a probe that contains a point mutation within the EBE (lanes 6 and 7 ) was added to the reaction. C, A rabbit antibody to E2F1 (2 $\mu \mathrm{g}$, lane 3; $5 \mu \mathrm{g}$, lane 4 ) or a control antibody (anti-HA antibody, $2 \mu \mathrm{g}$, lane 5; $5 \mu \mathrm{g}$, lane 6) was added to the EMSA reaction. Three protein-DNA complexes that are shown as specific EBE-protein complexes in $B$ (arrowheads) were blocked or super-shifted (bracket) by the addition of E2F1 antibody but not by control antibody.

the context of the $-245 / c d c 2$ reporter gene reduced significantly the ability of $\mathrm{KCl}$ withdrawal to induce $c d c 2$ promoter-mediated transcription (Fig. $2 \mathrm{~A}$ ). These results suggest that the EBE within the $c d c 2$ promoter plays a critical role in mediating activity deprivation-induced $c d c 2$ transcription.

Members of the E2F family of transcription factors bind the EBE in proliferating cells (Tommasi and Pfeifer, 1995; Takahashi et al., 2000; Rayman et al., 2002). We therefore tested whether the EBE within the $c d c 2$ promoter binds to an E2F family member in granule neurons. In EMSAs, the EBE formed protein-DNA complexes when incubated with nuclear extracts of cerebellar granule 
A

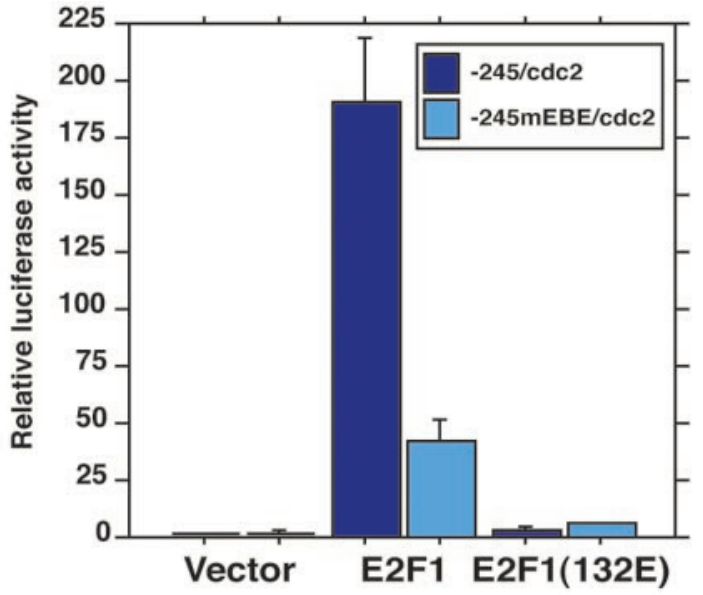

B
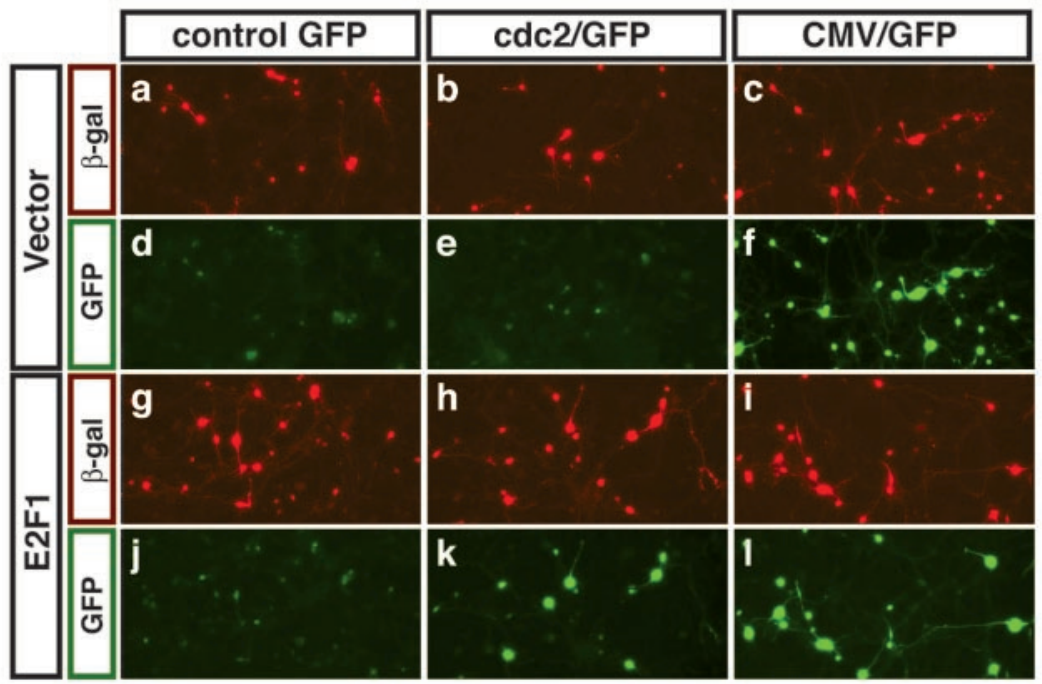

C
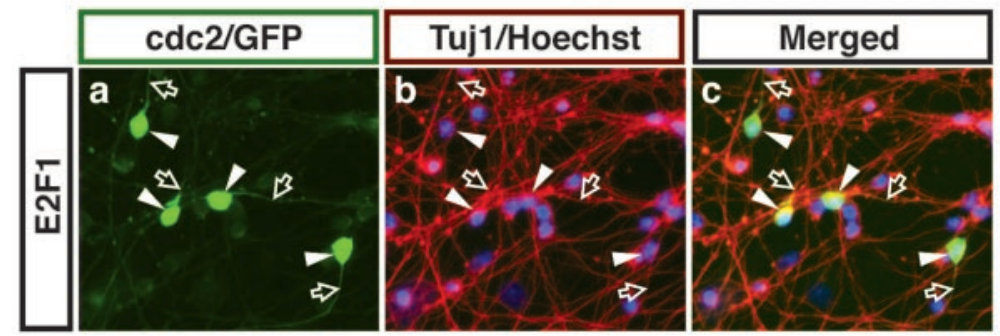

Figure 3. E2F1 activates $c d c 2$ promoter-mediated transcription in postmitotic cerebellar granule neurons. $A$, Cerebellar neuron cultures (P6 plus 2 DIV) were transfected with the $-245 / c d c 2$ or $-245 / \mathrm{mEBE} / \mathrm{cdc} 2$ luciferase reporter plasmids together with the EF-renilla reporter gene and an expression plasmid encoding E2F1, an E2F1 mutant in which the DNA-binding domain is mutated [E2F1(132E)], or their control vector. One day after transfection, transfected cells were harvested and subjected to a dual-luciferase assay. Normalized reporter activities are shown relative to the reporter activity of the $-245 / c d c 2$ luciferase gene that was cotransfected with the vector control plasmid. Values shown are mean \pm SEM $(n=4)$. The activity of the $-245 / c d c 2$ reporter gene was significantly increased by $\mathrm{E} 2 \mathrm{~F} 1$ (ANOVA; $p<0.001$ ) but not by $\mathrm{E} 2 \mathrm{~F} 1$ (132E). Mutation within the $\mathrm{EBE}(-245 / \mathrm{mEBE} / c d c 2)$ significantly decreased E2F1 induction of $c d c 2$ transcription (ANOVA; $p<0.001$ ). $B$, Cerebellar granule neurons were transfected with the control GFP, cdc2/GFP reporter gene, or CMV/GFP reporter gene together with an expression plasmid encoding E2F1 or its control vector and an expression plasmid encoding $\beta$-galactosidase $(\beta$-gal). Two days after transfection, cells were subjected to indirect immunofluorescence with an antibody to $\beta$-galactosidase, and GFP reporter gene activity was monitored by visualizing GFP in transfected cells. E2F1 induced the cdc2/GFP reporter. C, Cerebellar granule neuron cultures were transfected with the E2F1-expression vector together with the cdc2/GFP reporter gene. Transfected cultures were subjected to indirect immunofluorescence with an antibody to $\beta$-tubulin type III (Tuj1) that is expressed in postmitotic neurons, and GFP visualization was used to monitor the cdc2/GFP reporter activity. Cell bodies (arrowheads) and neurites (open arrows) of all GFP-positive cells also stained with the Tuj1 antibody. neurons (Fig. $2 B$ ). The incubation of excess cold wild-type EBE in the DNA binding reaction, but not of mutant $\mathrm{EBE}$ known to disrupt its binding to E2Fs, reduced partly or completely the formation of three protein-DNA complexes (Fig. $2 B$, arrowheads). These results suggest that the EBE within the $c d c 2$ promoter binds E2F transcription factors that are present in nuclear extracts of granule neurons. The three EBE-protein complexes were disrupted or supershifted with the addition of an antibody that recognizes E2F1 specifically (Fig. 2C, bracket), but not by a control antibody. There was an increased amount of EBE-binding activity in nuclear extracts of activity-deprived granule neurons (Fig. 2B), suggesting that activity deprivation stimulates the activity of endogenous E2F1 in neurons. These data suggest that granule neurons express E2F1 that binds to the EBE within the $c d c 2$ promoter and raised the possibility that E2F1 might mediate activity deprivation-induced $c d c 2$ transcription in cerebellar granule neurons.

\section{E2F mediates activity deprivation- induced $c d c 2$ transcription in postmitotic granule neurons}

The finding that the EBE of the $c d c 2$ promoter binds to E2F1 and mediates activity deprivation-induced $c d c 2$ transcription led us next to address the question of whether E2F mediates activity deprivation-induced $c d c 2$ transcription in cerebellar granule neurons. First, we asked whether E2F1 has the capacity to induce $c d c 2$ transcription in granule neurons, which are in a postmitotic state. We imagined that E2F1 that is expressed in membrane-depolarized granule neurons is maintained in a repressed state to prevent the induction of $c d c 2$ and of genes that might trigger reentry of neurons into the cell cycle. Therefore, to investigate the ability of E2F1 to induce transcription of the $c d c 2$ gene in granule neurons, we overexpressed E2F1 in granule neurons together with the $c d c 2-$ luciferase $(-245 / c d c 2)$ reporter plasmid. We found that overexpressed E2F1 strongly enhanced $c d c 2$ promoter-mediated transcription (Fig. $3 A$ ). In contrast to wild-type E2F1, a mutant $\mathrm{E} 2 \mathrm{~F} 1$ that is unable to bind to the EBE because of an amino acid substitution within the DNA binding domain of E2F1 [E2F1(132E)] (Johnson et al., 1993) failed to induce the $c d c 2$ promoter effectively (Fig. 3A). In addition, mutation of the EBE within the $c d c 2$ promoter $(-245 \mathrm{mEBE} / c d c 2)$ significantly inhibited E2F1-dependent transcriptional activation of the $c d c 2$ promoter, arguing against the in- 
terpretation that E2F1-induced $c d c 2$ transcription occurs via the squelching of transcriptional corepressors or through a mechanism that is independent of E2F binding to the $c d c 2$ promoter. Together, these results demonstrate the ability of E2F1 to induce $c d c 2$ transcription in granule neuron cultures.

Granule neuron cultures contain $>95 \%$ granule neurons, and the introduction of plasmids into these cultures in our transfections targets granule neurons selectively, because $99 \%$ of transfected cells are granule neurons (Konishi et al., 2002). Nevertheless, because E2F-mediated transcription might be much more effective in non-neuronal cells, we investigated the possibility that E2F1 induction of $c d c 2$ transcription in our experiments might arise predominantly from $c d c 2$ promoter activity in the nonneuronal cells. We therefore generated a construct in which the GFP reporter gene is driven by the $c d c 2$ promoter $(c d c 2 / \mathrm{GFP})$ (Fig. $3 B$ ). We transfected cerebellar granule neuron cultures with a GFP, $c d c 2 / \mathrm{GFP}$, or cytomegalovirus (CMV)/GFP reporter gene together with an expression plasmid encoding $\beta$-galactosidase. Cultures were fixed $2 \mathrm{~d}$ after transfection and subjected to indirect immunofluorescence using a mouse monoclonal antibody to $\beta$-galactosidase. The activity of the $c d c 2$ promoter was monitored by visualizing GFP fluorescence. In the absence of E2F1, the activity of GFP was very weak and near background fluorescence levels. In contrast, the expression of E2F1 strongly induced the $c d c 2 / \mathrm{GFP}$ reporter gene but had little effect on the control GFP reporter or CMV/GFP reporter gene (Fig. $3 B)$. In other experiments, we found that the cells that expressed the E2F1-induced $c d c 2$ promoter-mediated GFP also expressed the neuron specific $\beta$-tubulin type III (Fig. $3 C)$. Together, these results establish that $\mathrm{E} 2 \mathrm{~F} 1$ possesses the capacity to activate $c d c 2$ promoter-mediated transcription in postmitotic cerebellar granule neurons.

We next examined whether E2F1 has the ability to induce transcription of the endogenous $c d c 2$ gene in cerebellar granule neurons. We transfected cerebellar granule neurons with an expression plasmid encoding HA-tagged E2F1 or HA-tagged E2F1(132E). Two days after transfection, granule neurons were subjected to indirect immunofluorescence using a rabbit antibody to HA and a mouse monoclonal antibody to Cdc2. Robust endogenous Cdc2 immunoreactivity was detected in granule neurons in which wild-type E2F1 was expressed (Fig. 4A-C). In contrast, we detected weak endogenous $\mathrm{Cdc} 2$ immunoreactivity in E2F1(132E)-expressing granule neurons (Fig. 4D-F). The percentage of strong Cdc2-positive granule neurons was quantified and revealed that strong endogenous $\mathrm{Cdc} 2$ was detected in a large fraction $(82 \%)$ of E2F1-expressing granule neurons but only in $10 \%$ of E2F1(132E)-expressing granule neurons (Fig. 4G). These results suggest that the expression of E2F1 stimulates endogenous $\mathrm{Cdc} 2$ expression in cerebellar granule neurons.
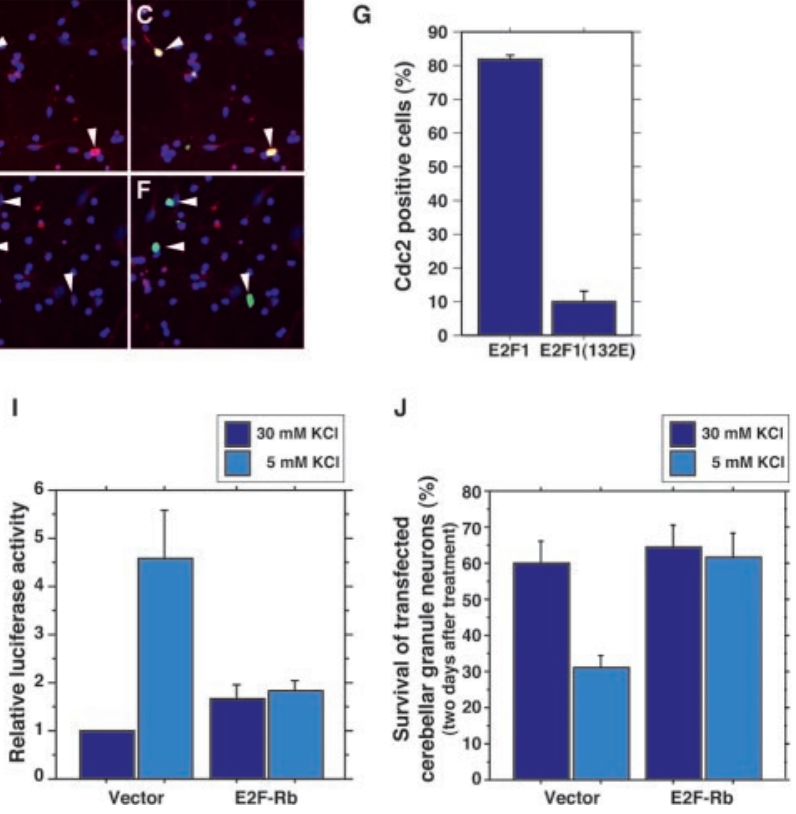

Figure 4. E2F1 mediates activity deprivation-induced $c d c 2$ transcription and apoptosis in cerebellar granule neurons. $A-F$, Cerebellar granule neurons (P6 plus 2 DIV) were transfected with an expression plasmid encoding HA-tagged E2F1 or HA-tagged (132E). Two days after transfection, cultures were subjected to indirect immunofluorescence using a rabbit anti-HA antibody

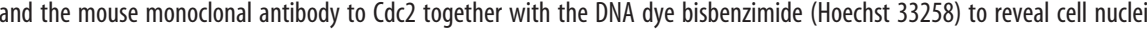
Arrowheads indicate HA-E2F1- or HA-E2F1(132E)-expressing neurons. G, Quantification of experiments in A-F showing the 作 expressing neurons (mean $\pm \mathrm{SEM} ; n=3 ; p<0.001 ; t$ test). $H_{\text {, Chromatin immunoprecipitation from cerebellar granule neuron }}$ cultures using no antibody (lane 1), a rabbit antibody to HA to serve as a control (lane 2), and an antibody against E2F1 (Iane 3). Precipitated chromatin was subjected to PCR analysis using a set of primers encompassing the EBE within the cdc2 promoter (as shown in the figure). Endogenous cdc2 promoter was specifically coprecipitated with immunoprecipitated E2F1 (lane 3). I, Cereector or an expression plasmid encoding the dominant interfering form of E2F (E2F-Rb), in which the E2F1 DNA-binding region granule neurons. Cerebellar granule neurons (P6 plus 2 DIV) were transfected with the E2F-Rb expression plasmid or the control vector together with an expression plasmid encoding $\beta$-galactosidase. One day after transfection, granule neurons were placed in full medium (30 mм KCl plus serum) or deprived of neuronal activity (5 mM KCl plus serum) for $2 \mathrm{~d}$. Transfected neurons were subjected to indirect immunofluorescence using the monoclonal antibody to $\beta$-galactosidase and the DNA dye bisbenzimide 33258). Cell survival and death were measured in $\beta$-galactosidase-expressing neurons based on the integrity of neurites and nucleus. $\mathrm{KCl}$ withdrawal significantly reduced the survival of vector-transfected granule neurons $(n=3 ;$ ANOVA; $p<0.05)$ but not of E2F-Rb-expressing granule neurons.

We next characterized the role of endogenous E2F in mediating $c d c 2$ expression in activity-deprived cerebellar granule neurons. To examine whether endogenous E2F might mediate transcription of the endogenous $c d c 2$ gene, we performed chromatin immunoprecipitation analysis. Chromatin was prepared from cerebellar granule neurons and was immunoprecipitated using no antibody, a control antibody, or an anti-E2F1 antibody together with protein A-Sepharose beads. Immunoprecipitated chromatin was subjected to PCR using primers designed to anneal to the $c d c 2$ promoter in a region encompassing the EBE (Fig. $4 H)$. We found that the endogenous $c d c 2$ promoter was coprecipitated with endogenous E2F1 (Fig. $4 H$ ). The results of control experiments using no antibody or control antibody supported the interpretation that the endogenous $c d c 2$ promoter and endogenous E2F1 coprecipitated specifically (Fig. $4 H$ ). These results suggest that the endogenous $c d c 2$ gene is a target of endogenous E2F1 in postmitotic neurons. Next, we tested the effect of a dominant interfering form of E2F, in which the DNA-binding 
A
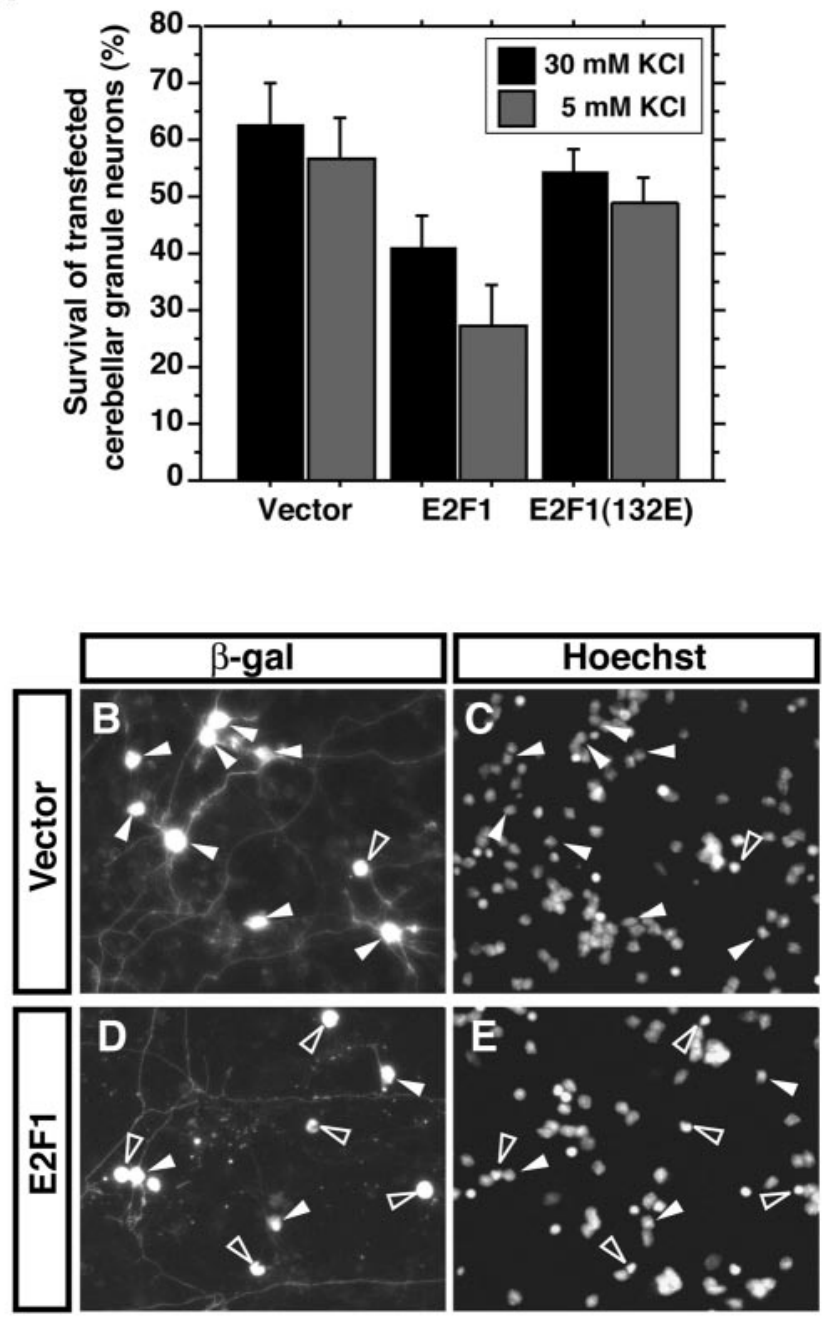

$\mathbf{F}$

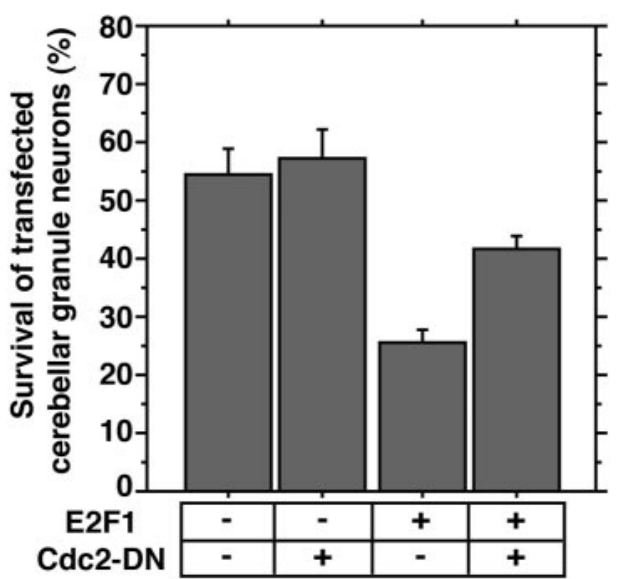

Figure 5. Cdc2 mediates E2F1-induced neuronal apoptosis. A, Cerebellar granule neurons (P6 plus 2 DIV) were transfected with the expression plasmid encoding E2F1, E2F1(132E), or their control vector together with an expression plasmid encoding $\beta$-galactosidase. One day after transfection, granule neurons were placed in full medium ( $30 \mathrm{~mm} \mathrm{KCl}$ plus serum) or deprived of neuronal activity ( $5 \mathrm{~mm} \mathrm{KCl}$ plus serum) for $24 \mathrm{hr}$. Transfected neurons were subjected to indirect immunofluorescence and cell survival assays as in Figure 4J. The expression of E2F1 significantly reduced the survival of cerebellar granule neurons [mean $\pm \mathrm{SEM} ; n=3$; ANOVA; $p<0.05$ (30 mm KCl), $p<0.005$ (5 mM KCl)]. However, E2F1(132E) had little effect on domain of E2F1 was fused to the repressor Rb (E2F-Rb) (Sellers et al., 1995, 1998), on the ability of $\mathrm{KCl}$ withdrawal to induce the $c d c 2$ promoter in cerebellar granule neurons. E2F-Rb is expected to inhibit endogenous E2F proteins by blocking their ability to induce transcription (Sellers et al., 1995, 1998). We found that E2F-Rb, when coexpressed with the $-3200 / c d c 2-$ luciferase reporter gene, abolished $\mathrm{KCl}$ withdrawal induction of the $c d c 2$ promoter (Fig. $4 I$ ). Together with the finding of chromatin immunoprecipitation experiments, these results suggest that endogenous E2F mediates neuronal activity deprivation-dependent $c d c 2$ transcription.

\section{The $\mathrm{E} 2 \mathrm{~F}-c d c 2$ cell-cycle pathway promotes granule} neuron apoptosis

Our results suggesting that E2F1 mediates activity deprivationinduced $c d c 2$ transcription raised the question of whether E2F1 and $\mathrm{Cdc} 2$ lie on a biochemical pathway that mediates activity deprivation-induced apoptosis of neurons. E2F1 has been demonstrated to promote apoptosis in postmitotic neurons including cerebellar granule neurons (O'Hare et al., 2000; Gendron et al., 2001; Liu and Greene, 2001b). Consistent with these observations, we found that the dominant interfering form of E2F (E2F$\mathrm{Rb})$, when expressed in granule neurons, blocked the ability of $\mathrm{KCl}$ withdrawal to induce apoptosis (Fig. 4J), suggesting that endogenous E2F proteins mediate activity deprivation-induced apoptosis of neurons.

The molecular mechanisms by which E2F1 promotes apoptosis remain to be elucidated. Because activity deprivation induces E2F-mediated $c d c 2$ transcription (this study) and because the activity of Cdc2 promotes granule neuron apoptosis (Konishi et al., 2002), we asked whether the proapoptotic function of E2F1 in cerebellar granule neurons is mediated via the induction and activation of Cdc2. We first established that the expression of E2F1 induces granule neuron apoptosis in our cultures. Granule neurons were transfected with an E2F1 expression plasmid or the control vector and were then maintained in full medium or deprived of membrane-depolarizing concentrations of $\mathrm{KCl}$ for just $24 \mathrm{hr}$ to obtain a negligible amount of activity withdrawalinduced apoptosis in vector-transfected cultures to allow the detection of apoptosis on E2F1 overexpression (Fig. 5A). Although the expression of E2F1 induced apoptosis in membranedepolarized cultures, E2F1-mediated apoptosis was more marked in cultures that were deprived of depolarizing concentrations of $\mathrm{KCl}$ (Fig. 5A-E), suggesting that activity deprivation further activates the ability of E2F1 to induce apoptosis or that additional activity deprivation-induced mechanisms cooperate with E2F1 to induce apoptosis. The expression of the mutant E2F1 protein [E2F1(132E)], that poorly binds to the EBE, failed to effectively induce neuronal apoptosis, suggesting that the binding of $\mathrm{E} 2 \mathrm{~F} 1$ to the promoter of responsive genes is necessary for E2F1 to stimulate transcription of apoptotic genes and thereby trigger apoptosis. We next asked whether Cdc2 might constitute an apoptotic gene target of E2F1 in granule neurons.

the survival of cerebellar granule neurons. $B-E$, Representative images of cerebellar granule neurons transfected with the control vector $(B, C)$ or the E2F1 expression plasmid $(D, E)$. In the vector control, several healthy neurons appear (closed arrowheads), whereas several E2F1transfected neurons are undergoing apoptosis (open arrowheads). $F$, Cerebellar granule neurons were transfected with the E2F1 expression plasmid together with Cdc2-DN or its vector control together with the $\beta$-galactosidase expression plasmid. Transfected neurons were deprived of neuronal activity ( $5 \mathrm{~mm} \mathrm{KCl}$ plus serum) for $24 \mathrm{hr}$ and subjected to indirect immunofluorescence and cell survival assay as in Figure $4 \mathrm{~J}$. Cdc2-DN significantly reduced E2F1-induced apoptosis (mean $\pm \mathrm{SEM} ; n=4 ;$ ANOVA; $p<0.01$ ). 
We determined whether the inhibition of $\mathrm{Cdc} 2$ activity rescues granule neurons from E2F1-induced apoptosis. We found that a dominant interfering form of Cdc2 in which an amino acid is mutated in the catalytic region (Cdc2-DN), when coexpressed with E2F1 in granule neurons, significantly reduced E2F1-induced apoptosis (Fig. $5 F$ ). These results indicate that $\mathrm{Cdc} 2$ is functionally downstream of E2F1, and that the E2F-Cdc2 cell-cycle pathway thus provides an apoptotic signal in postmitotic neurons.

The similarity in the ability of E2F1 to induce $c d c 2$ in both postmitotic and proliferating cells raised the question of the extent of similarity in the regulation of E2F1 function in two cell types. In proliferating cells, E2F1 regulates the expression of a large set of genes that promote DNA synthesis and replication (DeGregori et al., 1995; Dyson, 1998; Harbour and Dean, 2000; Ishida et al., 2001; Ren et al., 2002). We therefore asked whether the activation of the E2F-Cdc2 cell-cycle pathway in activity-deprived granule neurons also leads to the induction of genes that serve a role in DNA synthesis. We determined whether activity deprivation stimulates DNA synthesis in granule neurons. Cerebellar granule neuron cultures were incubated with bromodeoxyuridine for $24 \mathrm{hr}$. As expected, nonneuronal cells incorporated BrdU. However, we failed to detect BrdU-positive neurons in these cultures. These results indicate that despite the activation of the E2F-Cdc2 cell-cycle pathway in neurons on activity deprivation, the DNA synthesis machinery is not activated in granule neurons (Fig. 6A-D). Consistent with this conclusion, we found that although activity deprivation induced Cdc2 expression, activity deprivation failed to induce the expression of the DNA-synthesis related factors PCNA and Cdk2 in granule neurons (Fig. 6E). Together, our results suggest that activity deprivation induces the E2F-mediated expression of $\mathrm{Cdc} 2$ in neurons but fails to induce E2F-regulated genes that turn on the DNA synthesis machinery. The activation of the mitotic kinase Cdc2 in postmitotic neurons in the absence of DNA synthesis may thus comprise the trigger for apoptosis.

\section{Discussion}

In this study, we have characterized a cell-cycle mechanism that specifically mediates activity deprivation-induced apoptosis of postmitotic neurons. We have found that the mitotic kinase Cdc2 mediates apoptosis of cerebellar granule neurons with the deprivation of neuronal activity but not with growth factor withdrawal. Activity deprivation induces the expression of Cdc2, leading to Cdc2-mediated neuronal apoptosis, by stimulating transcription of the $c d c 2$ gene in granule neurons. An EBE within the $c d c 2$ promoter was found to bind to E2F1 and mediate activity deprivation-induced $c d c 2$ transcription in granule neurons. We found that endogenous E2F1 in granule neurons occupies the promoter of the endogenous $c d c 2$ gene in chromatinimmunoprecipitation analysis. Consistent with these results, we also found that inhibition of E2F protein by a dominant interfering form of E2F blocks activity deprivation-induced $c d c 2$ transcription. In other experiments, we found that the expression of E2F1 in granule neurons induces the expression of Cdc2, which
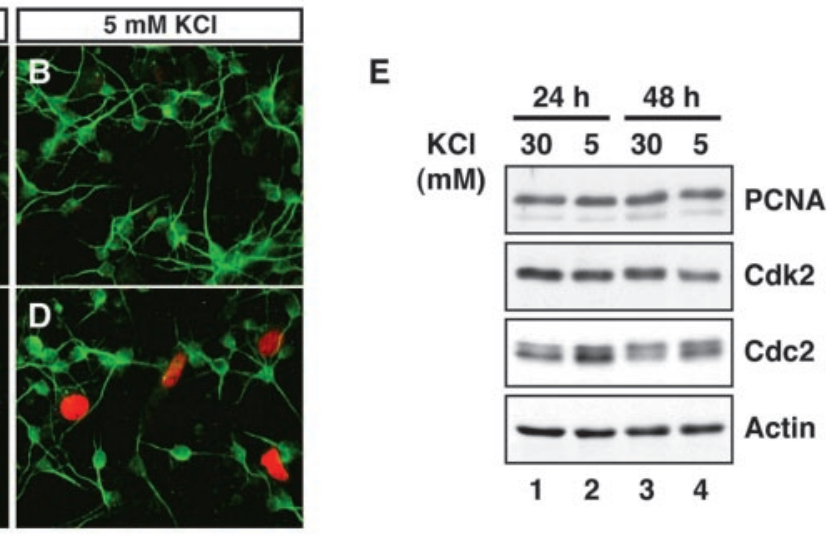

Figure 6. Activity deprivation does not stimulate DNA synthesis in cerebellar granule neurons. $A-D$, Cerebellar granule neuron (Po plus 2 DIV) were labeled with BrdU for $24 \mathrm{hr}$ in cultures that were in full medium ( $30 \mathrm{~mm} \mathrm{KCl}$ plus serum) or that were by immunofluorescence using a mouse monoclonal antibody that recognizes BrdU. Postmitotic granule neurons in culture were identified using a rabbit antibody that recognizes microtubule-associated protein 2 (MAP2). MAP2-negative non-neuronal cells 24 or $48 \mathrm{hr}$ were subjected to immunoblotting using an antibody to PCNA, Cdk2, Cdc2, or actin. Activity deprivation induced the

in turn mediates E2F1-induced apoptosis. Finally, although activity deprivation induces the E2F-mediated expression of Cdc2 in granule neurons, activity deprivation in neurons fails to induce the expression of genes that drive DNA synthesis and replication. Together, our findings define E2F-Cdc2 as a novel cell-cycle pathway in postmitotic neurons that selectively propagates an apoptotic signal during neuronal activity deprivation.

A role for reactivation of the cell-cycle machinery in apoptosis of postmitotic neurons was suggested nearly a decade ago (for review, see Liu and Greene, 2001a). However, the regulation of the cell-cycle machinery in postmitotic neurons and the mechanisms by which cell-cycle activation mediates neuronal apoptosis are just beginning to be elucidated. One of the early observations in this field was the finding that the withdrawal of nerve growth factor (NGF) from sympathetic neurons induces the expression of cyclin D1 expression in these neurons (Freeman et al., 1994). This observation was extended to a number of paradigms of neuronal apoptosis, including activity deprivation of cerebellar granule neurons and the exposure of neurons to DNA-damaging agents and other pathogenic stimuli (Park et al., 1997, 1998; Padmanabhan et al., 1999). In these studies, the induction of cyclin D1 was found to lead to the activation of D1-associated $c d k 4 / 6$, and inhibition of these kinases protected neurons against apoptosis (Park et al., 1997, 1998; Padmanabhan et al., 1999).

As in proliferating cells, an important target of CDK4/6 in neurons is the protein $\mathrm{Rb}$. The CDK4/6-induced phosphorylation of $\mathrm{Rb}$ is thought to control the $\mathrm{G}_{1}-\mathrm{S}$ transition in proliferating cells (Weinberg, 1995). During the early $G_{1}$ phase of the cell cycle, hypophosphorylated $\mathrm{Rb}$ binds to the transcription factor E2F and thereby represses E2F-mediated transcription (Chellappan et al., 1991; Dyson, 1998). However, the CDK-induced phosphorylation of $\mathrm{Rb}$ induces the derepression and transactivation of E2F-regulated genes leading to cell-cycle progression (Harbour et al., 1999). In postmitotic neurons, the CDK4/6-induced phosphorylation of $\mathrm{Rb}$ and consequent disinhibition of E2F have been linked to neuronal apoptosis in a number of settings including activity withdrawal-induced apoptosis of granule neurons (Padmanabhan et al., 1999; O’Hare et al., 2000). 
The mechanisms by which E2F mediates apoptosis of postmitotic neurons are beginning to be characterized. In a recent study by Liu and Greene (2001b), the repression of E2F-responsive genes was demonstrated to be required for neuronal survival. In this study, NGF withdrawal in sympathetic neurons and chemotoxin stimulation of cortical neurons was demonstrated to trigger the derepression of E2F-regulated genes leading to apoptosis (Liu and Greene, 2001b). It was also suggested in this study that transactivation of E2F-responsive genes is not required for neuronal apoptosis (Liu and Greene, 2001b).

In our study, we show that the transactivation function of E2F leads to the induction of Cdc2 expression and apoptosis in cerebellar granule neurons with activity deprivation. Our findings provide a novel link in neurons between the activity deprivationinduced $\mathrm{G}_{1}$ CDK-Rb-E2F1 pathway and the mitotic kinase Cdc2 culminating in the direct activation of the cell-death machinery via phosphorylation of the $\mathrm{BH} 3$-only protein $\mathrm{BAD}$. We have found that activity deprivation but not growth factor withdrawal induces the expression of $\mathrm{Cdc} 2$. Consistent with this result, we found that Cdc2 mediates activity deprivation-induced but not growth factor withdrawal-induced neuronal apoptosis. We also found that E2F1 triggers apoptosis of cerebellar granule neurons, and that E2F1-induced Cdc2 mediates the ability of E2F1 to promote apoptosis. Together, these findings suggest that the E2FCdc2 cell-cycle pathway specifically mediates the activity deprivation-induced neuronal apoptotic response.

In future studies, it will be important to address the question of whether in other neurons Cdc2 might be activated with apoptotic stimuli in addition to activity withdrawal. If Cdc2 but not E2F1 is the specificity determinant of activity deprivationinduced apoptosis, the $c d c 2$ promoter may provide a valuable biochemical endpoint in future studies for the identification and characterization of transcription factors that cooperate with E2F1 to specifically induce $\mathrm{Cdc} 2$ in activity-deprived postmitotic neurons. However, distinct E2F1-mediated mechanisms may mediate activity deprivation-induced apoptosis of granule neurons (this study) and apoptosis of sympathetic neurons with growth factor withdrawal or chemotoxin-induced apoptosis of cortical neurons (Liu and Greene, 2001b). The characterization of the distinct mechanisms regulating E2F function in postmitotic neurons in the different paradigms of neuronal apoptosis in these two studies may reveal additional specific signals that mediate activity deprivation-induced neuronal apoptosis.

The observation that neuronal activity deprivation induces E2F1-mediated $c d c 2$ transcription points to the similarity in the role of E2F1 in inducing Cdc2 in postmitotic neurons and proliferating cells. However, we found that much of the function of $\mathrm{E} 2 \mathrm{Fs}$, and $\mathrm{E} 2 \mathrm{~F} 1$ in particular, to stimulate $\mathrm{S}$ phase genes in proliferating cells is not recapitulated in postmitotic neurons. These observations carry a number of implications. First, they suggest that $\mathrm{Cdc} 2$ represents a select target of E2F in postmitotic neurons and point to specificity mechanisms that exist in postmitotic CNS neurons that confer E2F with the selective ability to induce $c d c 2$ transcription or that silence the majority of E2F-regulated genes. Investigation of these mechanisms might shed light on the postmitotic neuronal state. Second, our observation of Cdc2 triggering apoptosis of postmitotic neurons in the absence of DNA synthesis points to a similarity of Cdc2-mediated neuronal apoptosis and the role of premature $\mathrm{Cdc} 2$ activation in cycling cells culminating in apoptosis (Shi et al., 1994). It will be important to determine whether lessons from one situation might be applied to the other. Finally, it is interesting to compare the role of the cell-cycle machinery in apoptosis of neurons in the CNS and peripheral nervous system (PNS). A recent study revealed distinct responses of CNS and PNS neurons to expression of the transcription factor $\mathrm{N}$-myc that promotes cell-cycle progression in dividing cells (Wartiovaara et al., 2002). Whereas N-myc induced successful re-entry of sympathetic neurons into the cell cycle, N-myc induced apoptosis of cortical neurons (Wartiovaara et al., 2002). It will be interesting to compare the cell-cycle protein responses of PNS and CNS neurons to activity deprivation.

In conclusion, our findings suggest that the E2F-Cdc2 cellcycle pathway plays a critical role in neuronal apoptosis. Our study raises several questions. It will be important in future studies to determine the role of the E2F-Cdc2 cell-cycle pathway in the normal development of the mammalian brain. In addition, it will be important to determine how the E2F-Cdc2 cell-cycle pathway interacts with other signals that mediate activity deprivation-induced neuronal apoptosis. In this regard, the Jun$\mathrm{N}$-terminal kinase (JNK) signaling pathway is thought to play a critical role in apoptosis of granule neurons with the suppression of neuronal activity (Watson et al., 1998; Le-Niculescu et al., 1999). Interestingly, we found recently that JNK induces the phosphorylation of $\mathrm{BAD}$ at serine 128 and thereby activates BAD-mediated apoptosis (Donovan et al., 2002), raising the possibility that Cdc2 and JNK may converge on BAD to effectively induce the cell-death machinery in neurons, or that these kinases target BAD in a temporally specific manner in granule neurons (Donovan et al., 2002). Whether the regulation of the Cdc2 and JNK signaling pathways in activity-deprived neurons is coordinated remains to be determined. Finally, because neuronal death is thought to be a major pathophysiologic feature of several common neurologic disorders, including neurodegenerative diseases and stroke (Cotman, 1998; Pettmann and Henderson, 1998; Snider et al., 1999), it will also be interesting to determine whether the E2F-Cdc2 cell-cycle pathway contributes to neuronal apoptosis in these neurological diseases.

\section{References}

Alessi DR, Andjelkovic M, Caudwell B, Cron P, Morrice N, Cohen P, Hemmings BA (1996) Mechanism of activation of protein kinase B by insulin and IGF-1. EMBO J 15:6541-6551.

Altman J, Bayer S (1997) Development of the cerebellar system: in relation to its evolution, structure, and functions. New York: CRC.

Bonni A, Brunet A, West A, Datta SR, Takasu M, Greenberg ME (1999) Cell survival promoted by the Ras-MAPK signaling pathway by transcriptiondependent and -independent mechanisms. Science 286:1358-1362.

Busser J, Geldmacher DS, Herrup K (1998) Ectopic cell cycle proteins predict the sites of neuronal cell death in Alzheimer's disease brain. J Neurosci 18:2801-2807.

Campanero MR, Armstrong M, Flemington E (1999) Distinct cellular factors regulate the c-myb promoter through its E2F element. Mol Cell Biol 19:8442-8450.

Catterall WA (2000) Structure and regulation of voltage-gated Ca2 + channels. Annu Rev Cell Dev Biol 16:521-555.

Caviness Jr VS, Takahashi T, Nowakowski RS (1995) Numbers, time and neocortical neuronogenesis: a general developmental and evolutionary model. Trends Neurosci 18:379-383.

Chellappan SP, Hiebert S, Mudryj M, Horowitz JM, Nevins JR (1991) The E2F transcription factor is a cellular target for the RB protein. Cell 65:1053-1061.

Cohick WS, Clemmons DR (1993) The insulin-like growth factors. Annu Rev Physiol 55:131-153.

Cotman CW (1998) Apoptosis decision cascades and neuronal degeneration in Alzheimer's disease. Neurobiol Aging 19:S29-32.

Dalton S (1992) Cell cycle regulation of the human Cdc2 gene. EMBO J 11:1797-1804.

DeGregori J, Kowalik T, Nevins JR (1995) Cellular targets for activation by the E2F1 transcription factor include DNA synthesis- and G1/Sregulatory genes. Mol Cell Biol 15:4215-4224. 
Di Cunto F, Imarisio S, Hirsch E, Broccoli V, Bulfone A, Migheli A, Atzori C, Turco E, Triolo R, Dotto GP, Silengo L, Altruda F (2000) Defective neurogenesis in citron kinase knockout mice by altered cytokinesis and massive apoptosis. Neuron 28:115-127.

D’Mello SR, Galli C, Ciotti T, Calissano P (1993) Induction of apoptosis in cerebellar granule neurons by low potassium: inhibition of death by insulin-like growth factor I and cAMP. Proc Natl Acad Sci USA 90:10989-10993.

D’Mello SR, Borodezt K, Soltoff SP (1997) Insulin-like growth factor and potassium depolarization maintain neuronal survival by distinct pathways: possible involvement of PI 3-kinase in IGF-1 signaling. J Neurosci 10:1548-1560.

Donovan N, Becker EBE, Konishi Y, Bonni A (2002) JNK phosphorylation and activation of BAD couples the stress-activated signaling pathway to the cell death machinery. J Biol Chem 277:40944-40949.

Dudek H, Datta SR, Franke TF, Birnbaum MJ, Yao R, Cooper GM, Segal RA, Kaplan DR, Greenberg ME (1997) Regulation of neuronal survival by the serine-threonine protein kinase Akt. Science 275:661-665.

Dyson N (1998) The regulation of E2F by pRB-family proteins. Genes Dev 12:2245-2262.

Freeman RS, Estus S, Johnson Jr EM (1994) Analysis of cell cycle-related gene expression in postmitotic neurons: selective induction of Cyclin D1 during programmed cell death. Neuron 12:343-355.

Galli C, Meucci O, Scorziello A, Werge TM, Calissano P, Schettini G (1995) Apoptosis in cerebellar granule cells is blocked by high $\mathrm{KCl}$, forskolin, and IGF-1 through distinct mechanisms of action: the involvement of intracellular calcium and RNA synthesis. J Neurosci 15:1172-1179.

Gendron TF, Mealing GA, Paris J, Lou A, Edwards A, Hou ST, MacManus JP, Hakim AM, Morley P (2001) Attenuation of neurotoxicity in cortical cultures and hippocampal slices from E2F1 knockout mice. J Neurochem 78:316-324.

Harbour JW, Dean DC (2000) The Rb/E2F pathway: expanding roles and emerging paradigms. Genes Dev 14:2393-2409.

Harbour JW, Luo RX, Dei Santi A, Postigo AA, Dean DC (1999) Cdk phosphorylation triggers sequential intramolecular interactions that progressively block Rb functions as cells move through G1. Cell 98:859-869.

Hatten ME, Heintz N (1995) Mechanisms of neural patterning and specification in the developing cerebellum. Annu Rev Neurosci 18:385-408.

Ishida S, Huang E, Zuzan H, Spang R, Leone G, West M, Nevins JR (2001) Role for E2F in control of both DNA replication and mitotic functions as revealed from DNA microarray analysis. Mol Cell Biol 21:4684-4699.

Johnson DG, Schwarz JK, Cress WD, Nevins JR (1993) Expression of transcription factor E2F1 induces quiescent cells to enter $S$ phase. Nature 365:349-352.

Konishi Y, Lehtinen M, Donovan N, Bonni A (2002) Cdc2 phosphorylation of BAD links the cell cycle to the cell death machinery. Mol Cell 9:1005-1016.

Le-Niculescu H, Bonfoco E, Kasuya Y, Claret FX, Green DR, Karin M (1999) Withdrawal of survival factors results in activation of the JNK pathway in neuronal cells leading to Fas ligand induction and cell death. Mol Cell Biol 19:751-763.

Levkovitz Y, Baraban JM (2001) A dominant negative inhibitor of the Egr family of transcription regulatory factors suppresses cerebellar granule cell apoptosis by blocking c-Jun activation. J Neurosci 21:5893-5901.

Liu DX, Greene LA (2001a) Neuronal apoptosis at the G1/S cell cycle checkpoint. Cell Tissue Res 305:217-228.

Liu DX, Greene LA (2001b) Regulation of neuronal survival and death by E2F-dependent gene repression and derepression. Neuron 32:425-438.

McConnell SK (1995) Constructing the cerebral cortex: neurogenesis and fate determination. Neuron 15:761-768.

Miller TM, Johnson EM (1996) Metabolic and genetic analyses of apoptosis in potassium/serum-deprived rat cerebellar granule cells. J Neurosci 16:7487-7495.

O’Hare MJ, Hou ST, Morris EJ, Cregan SP, Xu Q, Slack RS, Park DS (2000) Induction and modulation of cerebellar granule neuron death by E2F-1. J Biol Chem 275:25358-25364.

Padmanabhan J, Park D, Greene LA, Shelanski ML (1999) Role of cell cycle regulatory proteins in cerebellar granule neuron apoptosis. J Neurosci 19:8747-8756.
Park DS, Levine B, Ferrari G, Greene LA (1997) Cyclin-dependent kinase inhibitors and dominant negative cyclin-dependent kinase 4 and 6 promote survival of NGF-deprived sympathetic neurons. J Neurosci 17:8975-8983.

Park DS, Morris EJ, Padmanabhan J, Shelanski ML, Geller HM, Greene LA (1998) Cyclin-dependent kinases participate in death of neurons evoked by DNA-damaging agents. J Cell Biol 143:457-467.

Pettmann B, Henderson CE (1998) Neuronal cell death. Neuron 20:633-647.

Putcha GV, Harris CA, Moulder KL, Easton RM, Thompson CB, Johnson Jr EM (2002) Intrinsic and extrinsic pathway signaling during neuronal apoptosis: lessons from the analysis of mutant mice. J Cell Biol 157:441-543.

Rayman JB, Takahashi Y, Indjeian VB, Dannenberg JH, Catchpole S, Watson RJ, te Riele H, Dynlacht BD (2002) E2F mediates cell cycle-dependent transcriptional repression in vivo by recruitment of an $\mathrm{HDAC} 1 / \mathrm{mSin} 3 \mathrm{~B}$ corepressor complex. Genes Dev 16:933-947.

Ren B, Cam H, Takahashi Y, Volkert T, Terragni J, Young RA, Dynlacht BD (2002) E2F integrates cell cycle progression with DNA repair, replication, and G(2)/M checkpoints. Genes Dev 16:245-256.

Schreiber E, Matthias P, Muller MM, Schaffner W (1989) Rapid detection of octamer binding proteins with "mini-extracts," prepared from a small number of cells. Nucleic Acids Res 17:6419.

Sellers WR, Rodgers JW, Kaelin Jr WG (1995) A potent transrepression domain in the retinoblastoma protein induces a cell cycle arrest when bound to E2F sites. Proc Natl Acad Sci USA 92:11544-11548.

Sellers WR, Novitch BG, Miyake S, Heith A, Otterson GA, Kaye FJ, Lassar AB, Kaelin Jr WG (1998) Stable binding to E2F is not required for the retinoblastoma protein to activate transcription, promote differentiation, and suppress tumor cell growth. Genes Dev 12:95-106.

Shi L, Nishioka WK, Th'ng J, Bradbury EM, Lithfield DW, Greenberg AH (1994) Premature p34cdc2 activation required for apoptosis. Science 263:1143-1145.

Shimizu M, Ichikawa E, Inoue U, Nakamura T, Nakajima T, Nojima H, Okayama H, Oda K (1995) The G1/S boundary-specific enhancer of the rat Cdc2 promoter. Mol Cell Biol 15:2882-2892.

Snider BJ, Gottron FJ, Choi DW (1999) Apoptosis and necrosis in cerebrovascular disease. Ann NY Acad Sci 893:243-253.

Sugarman JL, Schonthal AH, Glass CK (1995) Identification of a cell-typespecific and E2F-independent mechanism for repression of Cdc2 transcription. Mol Cell Biol 15:3282-3290.

Takahashi Y, Rayman JB, Dynlacht BD (2000) Analysis of promoter binding by the $\mathrm{E} 2 \mathrm{~F}$ and $\mathrm{pRB}$ families in vivo: distinct $\mathrm{E} 2 \mathrm{~F}$ proteins mediate activation and repression. Genes Dev 14:804-816.

Tommasi S, Pfeifer GP (1995) In vivo structure of the human Cdc2 promoter: release of a p130-E2F-4 complex from sequences immediately upstream of the transcription initiation site coincides with induction of Cdc2 expression. Mol Cell Biol 15:6901-6913.

van den Heuvel S, Harlow E (1993) Distinct roles for cyclin-dependent kinases in cell cycle control. Science 262:2050-2054.

Vincent I, Jicha G, Rosado M, Dickson DW (1997) Aberrant expression of mitotic Cdc2/cyclin B1 kinase in degenerating neurons of Alzheimer's disease brain. J Neurosci 17:3588-3598.

Wartiovaara K, Barnabe-Heider F, Miller FD, Kaplan DR (2002) N-myc promotes survival and induces S-phase entry of postmitotic sympathetic neurons. J Neurosci 22:815-824.

Watson A, Eilers A, Lallemand D, Kyriakis J, Rubin LL, Ham J (1998) Phosphorylation of c-Jun is necessary for apoptosis induced by survival signal withdrawal in cerebellar granule neurons. J Neurosci 18:751-762.

Weinberg RA (1995) The retinoblastoma protein and cell cycle control. Cell 81:323-330.

Wood KA, Dipasquale B, Youle RJ (1993) In situ labeling of granule cells for apoptosis-associated DNA fragmentation reveals different mechanisms of cell loss in developing cerebellum. Neuron 11:621-632.

Yamagishi S, Yamada M, Ishikawa Y, Matsumoto T, Ikeuchi T, Hatanaka H (2001) p38 Mitogen-activated protein kinase regulates low potassiuminduced c-Jun phosphorylation and apoptosis in cultured cerebellar granule neurons. J Biol Chem 276:5129-5133. 